\title{
Educação física escolar em unidades prisionais: elementos para se pensar sobre a educação "por entre as grades"1
}

\author{
School physical education in prison units: elements to \\ think about education "through the grates"
}

\section{Educación física escolar en unidades prisioneras: elementos para pensar sobre la educación "a través de las rejillas"}

iD Glauber César Cruz Custódio

Escola Estadual de Ouro Preto, Ouro Preto, Minas Gerais, Brasil.

russincruz1304@hotmail.com

iD Célia Maria Fernandes Nunes

Universidade Federal de Ouro Preto, Mariana, Minas Gerais cmfnunes1@gmail.com

(iD) Jairo Antônio da Paixão

Universidade Federal de Viçosa, Viçosa, Minas Gerais, Brasil. jairopaixao2004@yahoo.com.br

\begin{abstract}
Resumo: O objetivo do estudo foi identificar e analisar aspectos que caracterizam as aulas de Educação Física em unidades prisionais da Região dos Inconfidentes, MG. Para tal, foi realizada uma pesquisa qualitativa, a partir da entrevista semiestruturada com professores licenciados em Educação Física atuantes em escolas prisionais. Foi identificado que, devido às regras impostas pelas unidades prisionais, as aulas passam por adaptações e acontecem em salas de aula, com a proibição e/ou restrição do uso de materiais pedagógicos e de determinadas metodologias de ensino. Segundo os participantes, acresce a quase ausência dos movimentos corporais, o que acaba por subverter a lógica e os preceitos da
\end{abstract}

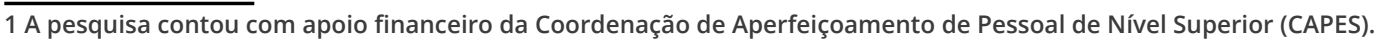


Educação Física escolar, alicerçadas no conceito de Cultura Corporal de Movimento e nos objetivos definidos pelos documentos legais.

Palavras-Chaves: Educação Física. Escola prisional. Atuação docente.

Abstract: The aim of the study was to identify and analyze aspects that characterize Physical Education classes in prison units in the Inconfidentes Region, MG. To this end, a qualitative research was carried out, based on a semi-structured interview with teachers licensed in Physical Education working in prison schools. It was identified that, due to the rules imposed by the prison units, classes undergo adaptations and take place in classrooms, with the prohibition and / or restriction of the use of teaching materials and certain teaching methodologies. According to the participants, there is an almost absence of body movements, which ends up subverting the logic and precepts of school Physical Education, based on the concept of Body Culture of Movement and objectives defined by legal documents.

Keywords: Physical Education. Prison school. Teaching performance.

Resumen: El objetivo del estudio fue identificar y analizar aspectos que caracterizan las clases de Educación Física en unidades penitenciarias de la Región de los Inconfidentes, MG. Para ello, se llevó a cabo una investigación cualitativa, basada en una entrevista semiestructurada a profesores titulados en Educación Física que laboran en escuelas penitenciarias. Se identificó que, debido a las normas impuestas por las unidades penitenciarias, las clases sufren adaptaciones y se desarrollan en las aulas, con la prohibición y / o restricción del uso de materiales didácticos y determinadas metodologías de enseñanza. Según los participantes, hay una casi ausencia de movimientos corporales, lo que acaba subvirtiendo la lógica y los preceptos de la Educación Física escolar, basada en el concepto de Cultura Corporal del Movimiento y objetivos definidos por los documentos legales.

Palabras clave: Educación Física. Escuela de la prisión. Rendimiento docente.

Submetido em: 24-10-2020

Aceito em: 07-07-2021 
Educação física escolar em unidades prisionais: elementos para se pensar sobre a educação... Glauber César Cruz Custódio • Célia Maria Fernandes Nunes • Jairo Antônio da Paixão

\section{Introdução}

A discussão e a compreensão do direito à educação têm adquirido centralidade no debate contemporâneo, tanto pela relação entre ensino e desenvolvimento econômico das sociedades, como por representar uma dimensão importante na redução das desigualdades sociais, constituindo, por isso mesmo, um dos mais importantes direitos sociais, que ao longo dos tempos não perderam e nem perderão sua atualidade (CURY, 2002).

Historicamente, a efetivação do direito à educação no Brasil foi um privilégio das elites. Como decorrência direta, tem-se que a formação da base produtiva do país ocorreu por meio de mão de obra escrava. Esse modelo colonizador, com matriz socioeconômica da educação de elite, excluía da escolaridade o grande contingente da população, composta, principalmente, por pessoas escravizadas (FERREIRA JUNIOR, 2010).

As normatizações que buscam amparar e garantir o direito à educação nas diferentes sociedades é marcadamente a resultante de um conjunto diversificado de eventos e documentos legais, ao longo do percurso histórico, que buscam assegurar o direito à educação a todos os seres humanos (CURY, 2014). Nesse contexto, a educação prisional surge como uma das dimensões do direito à educação daqueles que se encontram em situação de privação da liberdade.

Não obstante, a escola na ambiência prisional é convocada a alinhar-se a um projeto de transformação dos sujeitos, que permanecerão durante um período em questão, excluídos do convívio social, em constante vigilância, controlados, manipulados, adestrados por meio de tecnologias disciplinares (ONOFRE, 2012).

Cumpre destacar que a oferta de educação para sujeitos em privação de liberdade tem se efetivado como um direito de segunda categoria, conforme demonstrado por Onofre (2013), que aponta que o cotidiano da educação prisional revela um hiato entre o discurso oficial e a realidade. Além disso, as deficientes in- 
Educação física escolar em unidades prisionais: elementos para se pensar sobre a educação... Glauber César Cruz Custódio • Célia Maria Fernandes Nunes • Jairo Antônio da Paixão

fraestruturas dos estabelecimentos penais restringem o acesso ao direito à educação e à universalização da educação nesse contexto, no qual evidencia-se que, geralmente, as práticas são realizadas em locais adaptados, ou de uso compartilhado com os demais serviços (MIRANDA, 2016). A esse respeito, dados do Ministério da Justiça, apontam que, das mais de 1.800 unidades prisionais presentes no Brasil, nenhuma foi arquitetada, em sua origem, como espaço de estabelecimento educacional, ou seja, como uma escola para atendimento aos sujeitos privados de liberdade, sendo que, na realidade, são compostas por salas de aulas adaptadas ou as aulas são realizadas em espaços improvisados (SILVA; MOREIRA, 2011). Somado a isso, no que se refere aos materiais para as aulas em escolas prisionais, fundamentais para se garantir a educação de qualidade dos sujeitos que lá se encontram, Almeida (2014) aponta diferentes limitações quanto ao uso de determinados materiais, que vão impactar diretamente no cotidiano, dificultando e/ou impossibilitando a efetivação do planejamento pedagógico proposto. Nesse cotidiano da escola prisional, as atividades realizadas são carregadas pelo imprevisível, dessa forma, mesmo que o professor planeje as ações não é certo que ele consiga executá-las como foi programado (VIEIRA, 2013).

Nessa perspectiva, o objetivo da presente investigação foi identificar e analisar aspectos que caracterizam as aulas de Educação Física em unidades prisionais localizadas na Região dos Inconfidentes, MG. Os argumentos que conformam este estudo fundamentam-se no trabalho desenvolvido no Programa de PósGraduação em Educação da Universidade Federal de Ouro Preto como exigência parcial para a conclusão do curso de mestrado na área correspondente.

\section{Metodologia}

Tendo em vista o fenômeno estudado, a trilha científica das ciências humanas e sociais se mostrou a mais indicada para nor- 
Educação física escolar em unidades prisionais: elementos para se pensar sobre a educação... Glauber César Cruz Custódio • Célia Maria Fernandes Nunes • Jairo Antônio da Paixão

tear a sua averiguação. Desta forma, este estudo caracterizou-se como uma pesquisa de natureza qualitativa na qual, de acordo com Minayo (2011), trabalha-se com um universo de significados, motivos, aspirações, crenças, valores e atitudes. Isso corresponde a um espaço mais profundo das relações, dos processos e dos fenômenos, que não podem ser reduzidos à operacionalização de variáveis.

Como instrumento de coleta de dados, foi utilizada entrevista semiestruturada, conduzida e fundamentada nos estudos de Spradley (1979), que assinala a entrevista com características etnográficas como sendo um evento discursivo, que, por sua vez, pode ser descrito pelo modo de conduzir alguns diálogos em ocasiões ou encontros sociais. Essas entrevistas foram gravadas com um gravador de voz.

Participaram dessa investigação três professores de Educação Física, todos do sexo masculino, com média de idade de 33 anos, que se encontravam atuando em três unidades prisionais convencionais da Região dos Inconfidentes. A escolha dessa região se deu pela intenção de contribuir para compreensão de uma problemática regional, oferecendo um retorno às cidades onde a universidade se encontra inserida. Essas unidades prisionais localizam-se nas cidades de Mariana, Ouro Preto e Ponte Nova, no estado de Minas Gerais. Na seleção do grupo amostral, foram considerados os seguintes critérios de inclusão: docentes licenciados em Educação Física, que atuam com o componente curricular Educação Física em unidades prisionais localizadas na Região dos Inconfidentes, que aceitaram participar da pesquisa e assinaram o Termo de Consentimento Livre e Esclarecido. Vale ressaltar que estes participantes compõem todos os professores de Educação Física da referida região, reforçando a relevância da abrangência da investigação. Os nomes dos professores aqui adotados são fictícios, buscando preservar o seu anonimato.

Além disso, é significativo realçar que esses professores são oriundos de escolas prisionais, que subsistem dentro dos estabelecimentos prisionais, e que são um segundo endereço de uma 
Educação física escolar em unidades prisionais: elementos para se pensar sobre a educação... Glauber César Cruz Custódio • Célia Maria Fernandes Nunes • Jairo Antônio da Paixão

escola-polo da rede estadual, localizada na cidade da referida unidade prisional. As aulas acontecem nas salas de aula dos próprios estabelecimentos prisionais e, questões como reuniões pedagógicas e administrativas, assinaturas de documentos, conselhos de classe etc., são realizadas na escola-polo. Essas escolas prisionais são geridas pelo governo do estado de Minas Gerais, através da Secretária de Estado de Educação, que, a partir de um processo seletivo, fazem contratos anuais dos professores com as escolas-polos. O funcionamento dessas escolas prisionais é realizado sob a supervisão das Superintendências Regionais de Ensino.

Nessa perspectiva, destaca-se que a educação prisional acontece em conformidade com o Decreto Presidencial n 7.626/2011, que estabelece o Plano Estratégico de Educação no âmbito do sistema prisional, em parceria com o Ministério da Educação e o Ministério da Justiça, e que conta ainda com o auxílio dos Estados. No estado de Minas Gerais, foi elaborado o Plano Estadual de Educação nas Prisões (MINAS GERAIS, 2012), e, a partir disso, a educação prisional ocorre em unidades prisionais de municípios das diferentes regiões do estado de Minas Gerais.

$\mathrm{Na}$ análise dos dados, após a transcrição das informações contidas nas entrevistas, foi utilizada a técnica de análise de conteúdo (BARDIN, 2011; CAREGNATO; MUTTI, 2006). As autoras citadas identificam três etapas que configuram a técnica de análise de conteúdo: pré-análise, exploração do material e tratamento dos resultados e interpretação. A primeira etapa é uma fase de organização, que pode utilizar vários procedimentos, como: leitura flutuante, hipóteses, objetivos e elaboração de indicadores que fundamentem a interpretação. Na segunda, os dados são codificados a partir de unidades de registro. Finalmente, na última etapa é feita a categorização, que consiste na classificação dos elementos, segundo suas semelhanças e por diferenciação, com posterior reagrupamento em função de características comuns.

$\mathrm{Na}$ execução deste estudo, foram consideradas as diretrizes regulamentadas pela Resolução $n^{\circ} 466 / 12$ da Comissão Nacional de Ética em Pesquisa, sendo o projeto aprovado pelo Comitê de 
Educação física escolar em unidades prisionais: elementos para se pensar sobre a educação... Glauber César Cruz Custódio • Célia Maria Fernandes Nunes • Jairo Antônio da Paixão

Ética em Pesquisa da Universidade Federal de Ouro Preto, em 17 de outubro de 2017, conforme ofício CEP nº 2.232.241.

\section{Resultados e discussão}

A discussão dos resultados obtidos desenvolveu-se por meio da análise dos dados das entrevistas realizadas com os professores participantes, a bibliografia utilizada, que vinha ao encontro da temática abordada, e também, as posições assumidas pelos autores da investigação em relação ao tema. Desta forma, foi possível a compreensão e a discussão aprofundadas das categorias de análise que emergiram dos dados e que se encontram organizadas em três partes: a primeira busca conhecer a estruturação dos espaços físicos para as aulas de Educação Física; a segunda parte aborda as regras internas e suas implicações na prática do docente em Educação Física e, por fim, a terceira que analisa o interesse dos detentos em participar das aulas de Educação Física.

\section{Estruturação dos espaços físicos para as aulas de Educação Física}

$\mathrm{Na}$ ambiência escolar, uma das especificidades da Educação Física, que a diferencia dos demais componentes curriculares, refere-se à presença do movimento, que por sua vez, demanda espaços apropriados, como áreas abertas, quadras e, quando possível, ginásios. Subvertendo essa lógica, no que concerne aos espaços físicos nos quais acontecem as aulas de Educação Física, os professores indicaram que as aulas de todas as disciplinas, inclusive a Educação Física, acontecem exclusivamente dentro das salas de aula improvisadas, como são destacadas nos depoimentos que seguem. 
Educação física escolar em unidades prisionais: elementos para se pensar sobre a educação... Glauber César Cruz Custódio • Célia Maria Fernandes Nunes • Jairo Antônio da Paixão

[...] eu tenho apenas uma sala pequena para trabalhar [...] Por não se tratar de uma escola regular, existe a limitação espacial, né? Então é uma situação que é uma escola que oferece o que ela pode, né? [...] lógico que tem suas limitações. [...] Agora tem a situação de estar em um ambiente prisional, dentro de uma sala, em que se é permitido apenas dentro daquela sala. (Teodoro).

[...] então, quer dizer, é uma sala só, é uma cela com grade e tudo, tem um banheiro lá dentro e tem dois quadros na mesma sala. Então não tem divisão de sala, nem nada. [...] Então, assim, as aulas são divididas, quer dizer, tem professor dando aula do meu lado falando sobre uma coisa e eu falando sobre outra coisa do lado dele, tipo assim, a menos de cinco metros de distância. [...] o ideal era se tivesse um pátio, por exemplo, podia ser de cimento, de chão batido, mas não tem nenhum espaço. (Raimundo).

[...] dentro de uma sala de aula de menos de quarenta metros quadrados, que hoje formaram duas, é meio frustrante, porque como é que você vai fazer? Tem as carteiras, tem livros, têm não sei o que, como você vai fazer com uma aula de Educação Física? (Kalebe).

Estudos relacionados à identificação das contribuições da educação prisional para a ressocialização do indivíduo (MIRANDA, 2016; SALVALAGGIO, 2016) revelam que raramente as unidades prisionais são planejadas com salas de aula que apresentem condições de atender ao aluno privado de liberdade. Como decorrência, as práticas escolares no contexto carcerário geralmente acontecem em espaços inadequados, que têm outras finalidades ou que são de utilização compartilhada com outras destinações. Reitera-se que, no trato das diferentes práticas corporais nas aulas de Educação Física, o espaço físico que geralmente se tem para as aulas de Educação Física e a importância de materiais nas ações docente constituem exemplos de características específicas da disciplina (ILHA, 2012). 


\section{Regras internas e suas implicações na prática do docente em Educação Física}

Tendo em vista se tratarem de aulas de Educação Física em unidades prisionais, o rigor das regras internas configura-se como elemento interveniente nas práticas pedagógicas, como, por exemplo, a proibição do emprego de materiais pedagógicos como cordas, bolas, bambolês, materiais do atletismo, ou ainda daqueles que possam ocasionar cortes ou que sejam pontiagudos, a restrição das práticas corporais permitidas, bem como da adoção de estratégias metodológicas nas aulas. $O$ depoimento de um dos professores descreve com clareza a situação.

[...] eu não posso levar uma bola, não posso levar uma peteca, eu não tenho nada que tenha muito movimento que eu possa fazer lá. [...] não posso adentrar com corda, do atletismo não posso entrar com o dardo, lá tem essas limitações [...] eu não posso levar nada de pontiagudo [...] futebol de [...] prego sabe, que tem um monte de prego, era um que proibiram de levar, até cogitei a levar [...] (Raimundo).

A regra é que eles não podem sair dessa cela, então não tem como eu desenvolver nada, se eu tivesse pelo menos um pátio, poderia até ser uma quadra [...] (Raimundo).

Inconformados com a situação, alguns desses professores chegaram a apresentar propostas de mudanças ao setor pedagógico e à direção das unidades prisionais, no entanto, não obtiveram êxito. Dessa forma, numa perspectiva que sinaliza estratégias educativas para a minimização dos efeitos negativos, provenientes dos efeitos do rigor das regras presente nas aulas, os professores viram como via alternativa o uso da criatividade para o desenvolvimento das ações pedagógicas da disciplina, como se pode perceber em algumas falas. 
Educação física escolar em unidades prisionais: elementos para se pensar sobre a educação... Glauber César Cruz Custódio • Célia Maria Fernandes Nunes • Jairo Antônio da Paixão

[...] a limitação física ela te impõe ser mais criativo, isso te força a procurar maneiras diferentes de adequar sua aula [...] o que eu faço na minha aula é pegar um quadro que ia ser jogado fora transformei ele, entre aspas em uma mesa, que fica apoiada sobre outras mesas dentro da sala de aula, onde coloco uma rede amarrada em cima de duas cadeiras ao contrário para ser a rede da minha mesa [...] (Teodoro).

[...] tem que ser um educador que tem que usar muito a criatividade. Eu uso muito a criatividade, porque se não.... Porque se fosse para trabalhar somente com teoria com eles não ia ser bom (Kalebe).

Ainda nessa direção, visando reduzir as consequências negativas diante das circunstâncias permitidas e possíveis para as suas aulas nas escolas prisionais, esses professores trabalham para além das práticas corporais, que passam por adaptação das regras das modalidades esportivas, abordando também a saúde e outros temas relacionados à área de conhecimento por meio apresentação e discussões entre os alunos. De acordo com esses relatos dos professores, a Educação Física contribui para a vida dos alunos, no sentido de possibilitar que eles aprendam a importância de saber conviver com as regras e com o respeito ao outro. Nesse sentido, Moraes, Moraes e Ramos (2014), em uma investigação realizada acerca a prática de atividade física em um estabelecimento prisional, afirmam que o esporte, que se constitui como um dos conteúdos da Educação Física, quando adequadamente conduzido, poderia trazer importantes benefícios aos sujeitos em situação de privação de liberdade. Indo ao encontro dos dados de nossa pesquisa, os referidos autores afirmam que o esporte contribui para que os sujeitos em situação de privação de liberdade

consigam se adequar às regras e normas vigentes na sociedade durante e após o cumprimento da pena, bem como aprender a lidar com comportamentos transgressores (MORAES; RAMOS, 2014, p. 53). 
Educação física escolar em unidades prisionais: elementos para se pensar sobre a educação... Glauber César Cruz Custódio • Célia Maria Fernandes Nunes • Jairo Antônio da Paixão

É importante salientar que, mesmo que se esforcem e adotem algumas estratégias para enfrentar esses desafios, os professores participantes encontram limitações significativas em suas práticas pedagógicas no que se refere às possibilidades de conteúdos, em função da organização das escolas prisionais. Indo ao encontro do exposto, Onofre (2009) revela dificuldades evidentes para se desenvolver, de maneira efetiva, um programa de educação que se adeque à estrutura disciplinar de organização dos estabelecimentos prisionais.

Esses relatos que se referem à importância do uso da criatividade para o desenvolvimento dos conteúdos da Educação Física nas escolas prisionais nos levam a uma indagação: seria criatividade ou um mecanismo de sobrevivência para o professor desenvolver suas atividades pedagógicas no cenário da escola prisional na qual está inserido?

Tal reflexão leva a considerar a afirmação de Onofre (2010) ao postular que a docência numa escola prisional demanda ao professor adotar uma estratégia social de sobrevivência, buscando formas de agir diante das relações que se estabelecem com o processo de ensino, com a forma de ensinar, reflexão sobre o fazer pedagógico.

Assim, nessa situação de aulas de Educação Física, acontecendo somente dentro da sala e submetidas às rígidas regras de segurança, parece estar presente, de maneira implícita, a ideia de que dentro da sala é possível controlar os corpos dos sujeitos em situação de privação de liberdade, sob uma ideologia de que se busca criar "corpos dóceis", resultantes de um rigoroso processo de disciplinarização (FOUCAULT, 1999).

Diante desse cenário, outro aspecto que chama a atenção é a dificuldade de efetivação dos objetivos atribuídos à Educação Física, como aqueles descritos em documentos legais, como, por exemplo, os da Base Nacional Comum Curricular (BNCC, 2017). Nesse documento, a Educação Física, na educação básica, tem como função assegurar aos alunos a construção ou reconstrução 
Educação física escolar em unidades prisionais: elementos para se pensar sobre a educação... Glauber César Cruz Custódio • Célia Maria Fernandes Nunes • Jairo Antônio da Paixão

de um complexo de conhecimentos que possibilitem desenvolver a consciência do aluno no que concerne a seus movimentos e recursos para cuidado de si mesmo e dos outros, e desenvolver sua autonomia de modo a apropriar-se e utilizar a cultura corporal de movimento em variadas finalidades humanas, para sua participação autoral e confiante na sociedade. No entanto, questiona-se como se apropriar-se da cultura corporal de movimento diante das circunstancias, já apresentadas, em que se inserem as aulas de Educação Física nessas escolas prisionais.

\section{Interesse dos detentos em participar das aulas de Educação Física}

No que se refere à participação nas aulas, os professores relataram que os alunos são interessados, participativos e curiosos pelos conteúdos, não enfrentando problemas em relação à participação dos mesmos durante as aulas. Além disso, constata-se, com as falas dos participantes a indicação de um grande respeito, por parte dos alunos, pelos professores nas aulas ministradas nas escolas prisionais. Foi destacado ainda que, muitas vezes, os alunos das escolas prisionais têm mais respeito pelo professor do que alunos das escolas regulares. Esses dados coadunam os encontrados por Bessil (2015) sobre a prática docente em sistema prisional.

Todavia, apesar de os professores terem relatado que, na sua maioria, os alunos apresentam grande interesse pelas aulas, eles vivenciam alguns momentos de desinteresse. Essa situação acaba gerando um dilema em relação à disposição dos alunos para estudos e ou para a remição². Segundo os professores participantes dessa investigação, há situações em que eles percebem que muitos dos seus alunos demonstram ou relatam se interessarem mais pela remição, ou seja, a redução da pena pelos estudos devido à

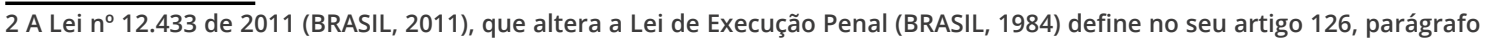
$1^{\circ}$, que o indivíduo poderá reduzir 1 dia de sua pena a cada 12 horas de frequência escolar, divididas, no mínimo, em 3 dias. 
Educação física escolar em unidades prisionais: elementos para se pensar sobre a educação... Glauber César Cruz Custódio • Célia Maria Fernandes Nunes • Jairo Antônio da Paixão

frequência nas aulas, do que pelos estudos propriamente ditos. Como se destaca nesse depoimento:

[...] e aí têm várias pessoas que falam que estão lá para diminuir a pena, né? Que não querem estudar, que não têm nenhum tipo de objetivo de estarem lá, só ganharem o tempo para diminuir a pena mesmo (Raimundo).

Em um estudo sobre a função da prisão, da pena e da educação prisional (SILVA; MOREIRA, 2011), os autores afirmam que a remição pelos estudos é elogiável em seu propósito, no entanto, desastrosa nos critérios estabelecidos. Segundo os autores, não se leva em consideração os objetivos e finalidades da educação, uma vez que se condiciona a remição das penas apenas à frequência na escola prisional, sem depender de conclusão de modalidade, ciclo, ou grau de estudos. Nessa direção, o estudo sobre avaliação da aprendizagem de sujeitos em situação de privação de liberdade, desenvolvido por Soares (2015), menciona que especialistas temem a transformação da educação prisional em uma forma simples de o presidiário passar o tempo e garantir a diminuição de sua pena. Logicamente, seria ingênuo afirmar que os detentos procurariam as escolas prisionais unicamente para obter conhecimento ou pelo desejo de emancipação pela educação. Desejam também diminuir a pena, mas a remição pelo estudo não pode objetivar apenas o encurtamento da pena do detento. Sobretudo, as escolas prisionais e os componentes escolares que o aluno vivencia devem ser compreendidos também sob os preceitos e objetivos educacionais.

\section{Considerações finais}

Diante das constatações obtidas por meio desta investigação, é possível afirmar que a análise realizada, cujo eixo norteador foi identificar e analisar aspectos que caracterizam as aulas 
Educação física escolar em unidades prisionais: elementos para se pensar sobre a educação... Glauber César Cruz Custódio • Célia Maria Fernandes Nunes • Jairo Antônio da Paixão

de Educação Física em unidades prisionais localizadas na Região dos Inconfidentes, no estado de Minas Gerais, forneceu elementos que despertam para uma reflexão sistemática sobre a Educação Física escolar em uma ambiência que dista da escola básica regular, e por sua da prática pedagógica de professores atuantes no contexto em questão.

Nesse cenário, embora haja diversas dimensões sendo discutidas e apontadas pela literatura, outras caminhando para isso, há ainda muito a se discutir no que se refere ao direito à educação para grupos que parecem estarem à margem da sociedade e fora do contexto da educação ofertada em espaços escolares comuns, como é o caso dos sujeitos em situação de privação de liberdade que acessam a educação em unidades prisionais.

As aulas de Educação Física ajustadas para acontecerem numa sala de aula, desprovida de movimentos corporais, subverte a lógica e preceitos da Educação Física escolar, alicerçadas no conceito de Cultura Corporal de Movimento. Ademais, a proibição e/ ou restrição do uso de materiais pedagógicos e de determinadas metodologias de ensino, próprios para a vivência de determinas práticas corporais limita significativamente as ações dos professores, atingindo negativamente $o$ alcance dos objetivos educacionais da Educação Física, como aqueles constantes em documentos oficiais, como por exemplo, na BNCC.

Ademais, tendo em vista a política de humanização e universalização da educação através das diferentes normatizações já promulgadas, é possível descrever que a Educação Física, desenvolvida nesses espaços prisionais, encontra-se desalinhada dos objetivos e preceitos dessas normatizações, por exemplo, no que diz respeito à adequação do espaço físico e das instalações para as ações de educação nesses locais, desconsiderando o direito de aprendizagem dos sujeitos em situação de privação de liberdade.

Nesse sentido, apesar de todas as limitações que caracterizam as aulas de Educação Física em unidades prisionais, os professores buscam humanizar suas aulas e adotam estratégias de modo a mi- 
Educação física escolar em unidades prisionais: elementos para se pensar sobre a educação... Glauber César Cruz Custódio • Célia Maria Fernandes Nunes • Jairo Antônio da Paixão

nimizar a problemática na qual estão inseridos, buscando, através de suas criatividades e conhecimentos, promover os benefícios da Educação Física, para a vida dos alunos em situação de privação de liberdade, que Ihes são possibilitados. Apesar dos dilemas, acredita-se que $o$ interesse dos alunos pelas aulas, o respeito pelos professores, e os benefícios da Educação Física e da educação no âmbito geral para os detentos, configuram-se elementos que levam a se pensar na necessidade de políticas públicas voltadas para a educação na ambiência prisional. Nessa direção, tendo em vista o seu potencial transformador, a educação se faz uma aliada poderosa no processo de ressocialização dos detentos.

E por fim, ressalta-se que, dentre os desafios que se fazem presentes, a atuação do professor em escolas prisionais não pode ser transformada e utilizada apenas como um mecanismo para redução da pena dos alunos, mas também deve ser compreendida sob os preceitos e objetivos educacionais.

\section{Referências}

ALMEIDA, C. V. A. A professora nos entremuros do cárcere.

2014. 234f. Tese (Doutorado em Educação e Contemporaneidade) - Universidade do Estado da Bahia, Salvador, 2014.

BARDIN, L. Análise de Conteúdo. Lisboa: Edições 70, 2011. BESSIL, M. H. A prática docente de educação de jovens e adultos no sistema prisional: um estudo da psicodinâmica do trabalho. 2015. 217f. Dissertação (Mestrado em Psicologia social e Institucional) - Universidade Federal do Rio grande do Sul, Porto Alegre, 2015.

BRASIL. Ministério da Educação. Secretaria da Educação Básica.

Base Nacional Comum Curricular. Terceira versão. Brasília: MEC 2017. Disponível em: http://portal.mec.gov.br/index.php?option=com_docman\&view=download\&alias=79601-anexo-texto-b- 
Educação física escolar em unidades prisionais: elementos para se pensar sobre a educação... Glauber César Cruz Custódio • Célia Maria Fernandes Nunes • Jairo Antônio da Paixão

ncc-reexportado-pdf-2\&category_slug=dezembro-2017-pdf\&Itemid=30192 Acesso em: 22 out. 2020.

CAREGNATO, R. C. A.; MUTTI, R. Pesquisa qualitativa: análise de discurso versus análise de conteúdo. Texto \& Contexto Enfermagem. Florianópolis, v. 15, n. 4, p. 679-84. out.-dez. 2006. CURY, C. R. J. Direito à educação: direito à igualdade, direito à diferença. Cadernos de Pesquisa, São Paulo, n. 116, p. 245-262, jun. 2002.

CURY, C. R. J. Educação e direito à educação no Brasil: um histórico pelas Constituições. Belo Horizonte: Mazza Edições, 2014.

FERREIRA JUNIOR, A. História da educação brasileira: da colônia ao século XX. São Carlos: EdUFSCar, 2010. (Coleção UAB-UFSCar). FOUCAULT, M. Vigiar e Punir. 20. ed. Petrópolis: Vozes, 1999. ILHA, F. R. S. O professor iniciante e a educação física escolar: desafios que se somam. 2012. In: SEMINÁRIO DE PESQUISA EM EDUCAÇÃO DA REGIÃO SUL, 9, 2012, Caxias do Sul. Anais... Caxias do Sul, 2012. p. 1-16.

MINAYO, M. C. S. (Org.) Pesquisa Social: teoria, método e criatividade. 30. ed. Petrópolis: Vozes, 2011.

MIRANDA, J. M. C. Educação de jovens e adultos: escola no cárcere e ressocialização de mulheres cearenses no regime semiaberto. 2016. 203f. Tese (Doutorado em Educação) Universidade Federal do Ceará, Fortaleza, 2016.

MORAES, A. M.; DE MORAES, B. M.; RAMOS, V. M. A prática da atividade física no presídio: o que pensam os apenados? Caderno de Educação Física e Esporte, Marechal Cândido Rondon, v. 12, n. 1, p. 47-54, 2014.

ONOFRE, E. M. C. Políticas de formação de educadores para os espaços de restrição e de privação de liberdade. Revista Eletrônica de Educação, v. 7, n. 1, p. 137-158, 2013.

ONOFRE, E. M. C. Desafio histórico na educação prisional brasileira: ressignificando a formação de professores... um quê de utopia? Revista HISTEDBR On-Line, v. 12, n. 47, p. 205-219, 2012. 
Educação física escolar em unidades prisionais: elementos para se pensar sobre a educação... Glauber César Cruz Custódio • Célia Maria Fernandes Nunes • Jairo Antônio da Paixão

ONOFRE, E. M. C. Docência na prisão: professores duplamente iniciantes, aprendendo com os pares e com o contexto. In: CONGRESO INTERNACIONAL SOBRE PROFESORADO PRINCIPIANTE E INSERCIÓN PROFESIONAL A LA DOCÊNCIA, 2, Buenos Aires, 2010. Anais... Buenos Aires, 2010.

ONOFRE, E. M. C. Educação Escolar na Prisão na Visão dos Professores: um hiato entre o proposto e o vivido. Reflexão e Ação, Cidade, v. 17, n. 1, p. 227-244, 2009.

SALVALAGGIO, L. R. Organização do trabalho pedagógico na educação prisional. 2016. 111 f. Dissertação (Mestrado em Educação) - Universidade Tuiuti Do Paraná, Curitiba, 2016.

SILVA, R.; MOREIRA, F. A. O projeto político-pedagógico para a educação em prisões. Em Aberto, Brasília, v. 24, n. 86, p. 89-103, 2011.

SOARES, C. P. G. Primeira escola prisional do Ceará: a avaliação da aprendizagem dos alunos privados de liberdade. 2015. 258 f. Dissertação (Mestrado em Educação) - Universidade Federal Do Ceará, Fortaleza, 2015.

SPRADLEY, J. P. The ethnographic interview. Florida: Harcourt Brace Jovanovich, 1979.

VIEIRA, E. L. G. A cultura da escola prisional: entre o instituído e o instituinte. Educação \& Realidade, Porto Alegre, v. 38, n. 1, p. 93-112, 2013.

\section{Publisher}

Universidade Federal de Goiás. Faculdade de Educação Física e Dança. Publicação no Portal de Periódicos UFG. As ideias expressadas neste artigo são de responsabilidade de seus autores, não representando, necessariamente, a opinião dos editores ou da universidade. 